\title{
Correlation of Gankyrin oncoprotein overexpression with histopathological grade in prostate cancer
}

\author{
M. MATBOU RIAHI ${ }^{1}$, N. SHARIFI SISTANI ${ }^{2}$, P. ZAMANI ${ }^{1}$, K. ABNOUS ${ }^{3}$, K. JAMIALAHMADI ${ }^{4,1, *}$ \\ ${ }^{1}$ Department of Medical Biotechnology, School of Medicine, Mashhad University of Medical Sciences, Mashhad, Iran; ${ }^{2}$ Department of Pathology, \\ Ghaem Hospital, Mashhad University of Medical Sciences, Mashhad, Iran; ${ }^{3}$ Pharmaceutical Research Center, Department of Medicinal Chemistry, \\ Mashhad University of Medical Sciences, Mashhad, Iran; ${ }^{4}$ Biotechnology Research Center, Mashhad University of Medical Sciences, Mashhad, Iran.
}

*Correspondence: jamialahmadikh@mums.ac.ir

Received November 21, 2016 / Accepted February 1, 2017

\begin{abstract}
Prostate cancer is the second most commonly diagnosed cancer among men worldwide. Identifying new prognostic and predictive biomarkers will help stratification of prostate cancer patients for a better treatment. Gankyrin is a novel oncoprotein which regulates cell cycle and protein degradation. Gankyrin overexpression correlated with the malignant phenotypes and promotes the tumorigenicity and metastasis in many cancers. However, there are not any reports on the role of Gankyrin in prostate cancer. Therefore, this study was designed to investigate the expression of Gankyrin in prostate cancer and analyze its correlation with some clinicopathological characteristics. We characterized the expression of gankyrin in fifty five prostate cancer specimens and twenty non-cancerous tissues by immunohistochemical staining and the results were correlated with clinical characteristics and pathological parameters.

Results showed that Gankyrin was expressed in 41 of 55 (74\%) prostate cancer patients and its expression was significantly higher than corresponding adjacent normal tissues $(\mathrm{p}<0.001)$. Gankyrin overexpression was significantly correlated with histopathological tumor grade, Gleason score and tumor differentiation $(\mathrm{P}=0.002)$. These findings showed that Gankyrin is mainly overexpressed in high grade prostate tumors so it may have a significant role in prostate cancer progress and it May serve as a useful biomarker for the identification of aggressive prostate cancers.
\end{abstract}

Key words: Gankyrin, prostate cancer, immunohistochemistry, oncoprotein

Prostate cancer $(\mathrm{PCa})$ remains the most common non-skin cancer of men and the second leading cause of cancer related deaths in the USA [1]. The projection of cancer incidence shows that prostate cancer will remain the second cancer for the next 20 years in the USA (2]. Epidemiologic studies revealed that there is a considerable heterogeneity in the mortality rates and incidence of prostate cancer among different countries, probably due to the variable penetrance of some risk factors such as age, race, genetics, diet and environmental factors. The incidence of prostate cancer is high in Western Europe and North America, intermediate in Africa and Eastern Europe, and low in Asia [3]. However, the incidence of prostate cancer in developing countries including Iran has risen dramatically over the past decades and it is the third most common cause of cancer death among Iranian men [4, 5]. Long-term ineffectiveness of current therapies for prostate cancer and limited data on the molecular mechanisms involved in initiation and progression of prostate cancer stimulated an increasing interest in understanding the molecular aspects of prostate cancer tumorigenesis [6]. New molecular markers are clinically important as they can increase the effectiveness of detection and even enhancing differential prognosis and therapy for prostate cancer patients [7]. Furthermore, as the accuracy of the pathologic diagnosis of this malignant tumor is critical for optimal patient care, it is necessary to introduce and assess novel histopathological and molecular markers for a more reliable diagnosis in prostate cancer patients to reduce unnecessary interventions based on a reliable estimate about cancer aggressiveness [8].

Gankyrin, also known as PSMD10 or p28GANK, is a novel oncogenic protein, and is highly conserved in mammals. Gankyrin has diverse physiological functions and plays important roles in cell cycle progression and apoptosis. Its tumorigenic function is mainly through binding to a different 
proteins including MDM2, pRb, p53 and cyclin-dependent kinase (CDK) [9-11]. Phosphorylation and degradation of $\mathrm{pRb}$ due to interaction with Gankyrin, leads to activation of the E2F transcription factor. In addition, Gankyrin binding to MDM2 promotes ubiquitination and proteasomal degradation of p53. Gankyrin also interacts with NF-kB and suppresses its activity via acetylation [12]. Therefore, this oncogene has a significant role in evade of apoptosis, cell proliferation, promoting tumorigenicity, angiogenesis and metastasis [9-11, 13]. Although p28GANK is overexpressed in multiple malignancies such as hepatocellular carcinoma (HCC) [14], breast cancer [13], cervical carcinoma [15] and pancreatic cancer [16], little is known about the role of this oncoprotein in prostate cancer. In the present study, for the first time we evaluated the expression level of Gankyrin protein in prostate cancer tissues, and explore its association with clinicopathologic parameters.

\section{Patients and methods}

Patients and tissue samples. The paraffin-embedded tissue samples from 55 patients diagnosed with prostate cancer were stained immunohistochemically. These tissues have been collected from prostate needle core biopsies over the period 2009-2013 at Department of Surgery, Ghaem Hospital, Mashhad University of Medical Sciences, Mashhad, Iran. The median age of patients was 75.5 years (rang 53-97). There were 17 cases of low grade, 3 cases of intermediate grade and 35 cases of high grade. The other clinicopathological characteristics of patients are summarized in Table 1. In addition, 20 specimens of normal prostates from exeresis for non-prostatic cancer diseases in the department of urology of Ghaem hospital, Mashhad University of Medical Sciences from 2010 to 2013 were used as control. All speciments were rechecked by two independent pathologists and confirmed by $H \& E$ staining.

Immunohistochemical staining. Four-micrometer-thick sections of formalin-fixed, paraffin-embedded tissue blocks were used for immunohistochemical analysis. The tissue sections were deparaffinized in xylene and therefore rehydrated through graded concentrations of ethanol. Blocking of endogenous peroxidase activity with $3 \%$ hydrogen peroxide was conducted for $15 \mathrm{~min}$, after that heat-induced antigen retrieval was performed using EDTA Tris buffer ( $\mathrm{pH}$ 7.4) in a $94-98^{\circ} \mathrm{C}$ water bath for $30 \mathrm{~min}$. The sections were then incubated with the rabbit primary polyclonal antibody against Gankyrin (Santa Cruz, CA, 1/200) followed by incubation with a secondary antibody (Biogenex) at room temperature. The tissue sections were visualized with 3, 3-diaminobenzidine $(\mathrm{DAB})$ chromogen and counterstained with hematoxylin for 30 seconds. Finally, dehydrated slides were mounted and viewed with a light microscope (Nikon, Elipse E200) coupled with a digital camera. Two negative controls were used; first, the primary antibody was replaced with normal mouse IgG and second, it was replaced with PBS. Human urinary bladder tissue was used for positive control.

Interpretation of immunostaining. The cellular location and intensity of staining were evaluated by two pathologists without prior information on clinicopathological data for each individual case. Gankyrin expression was evaluated according to the ratio of positive cells for Gankyrin immunoreactivity and intensity in ten random fields of each section. As p28GANK is a shuttle protein, both distinct nuclear and cytoplasmic staining was considered as positive. The data was evaluated using the following semiquantitative scoring method with considering both intensity and extent of Gankyrin immunoreactivity.

Table 1. Clinicopathologic parameters and its correlation with Gankyrin overexpression in prostate cancer patients.

\begin{tabular}{|c|c|c|c|c|c|c|}
\hline \multirow[b]{3}{*}{ Category } & \multicolumn{6}{|c|}{ Gankyrin expression } \\
\hline & \multicolumn{3}{|c|}{ Negative } & \multicolumn{3}{|c|}{ Positive } \\
\hline & Total (\%) & - & + & ++ & +++ & P value \\
\hline Age (yr) & & & & & & 0.554 \\
\hline$\leq 75$ years & $23(44.2)$ & 7 & 7 & 3 & 6 & \\
\hline$>75$ years & $29(55.8)$ & 7 & 6 & 7 & 9 & \\
\hline Differentiation & & & & & & $<0.001$ \\
\hline Poor & $30(57.7)$ & 1 & 3 & 8 & 18 & \\
\hline Moderate & $5(9.6)$ & 3 & 2 & 0 & 0 & \\
\hline Well & $17(32.7)$ & 10 & 7 & 0 & 0 & \\
\hline Tumor grade & & & & & & $<0.001$ \\
\hline Low & $17(30.9)$ & 12 & 4 & 0 & 1 & \\
\hline Intermediate & $3(5.4)$ & 1 & 2 & 0 & 0 & \\
\hline High & $35(63.6)$ & 1 & 1 & 10 & 17 & \\
\hline Gleason score (GS) & & & & & & $<0.001$ \\
\hline $\mathrm{GS}<7$ & $23(43.4)$ & 13 & 9 & 0 & 1 & \\
\hline $\mathrm{GS} \geq 7$ & $30(56.6)$ & 1 & 4 & 9 & 16 & \\
\hline
\end{tabular}

Gankyrin staining was graded as negative (-score: 0), weak (+: score: 1-3), moderate (++: score: 4-6), and strong (+++: 7-9) 

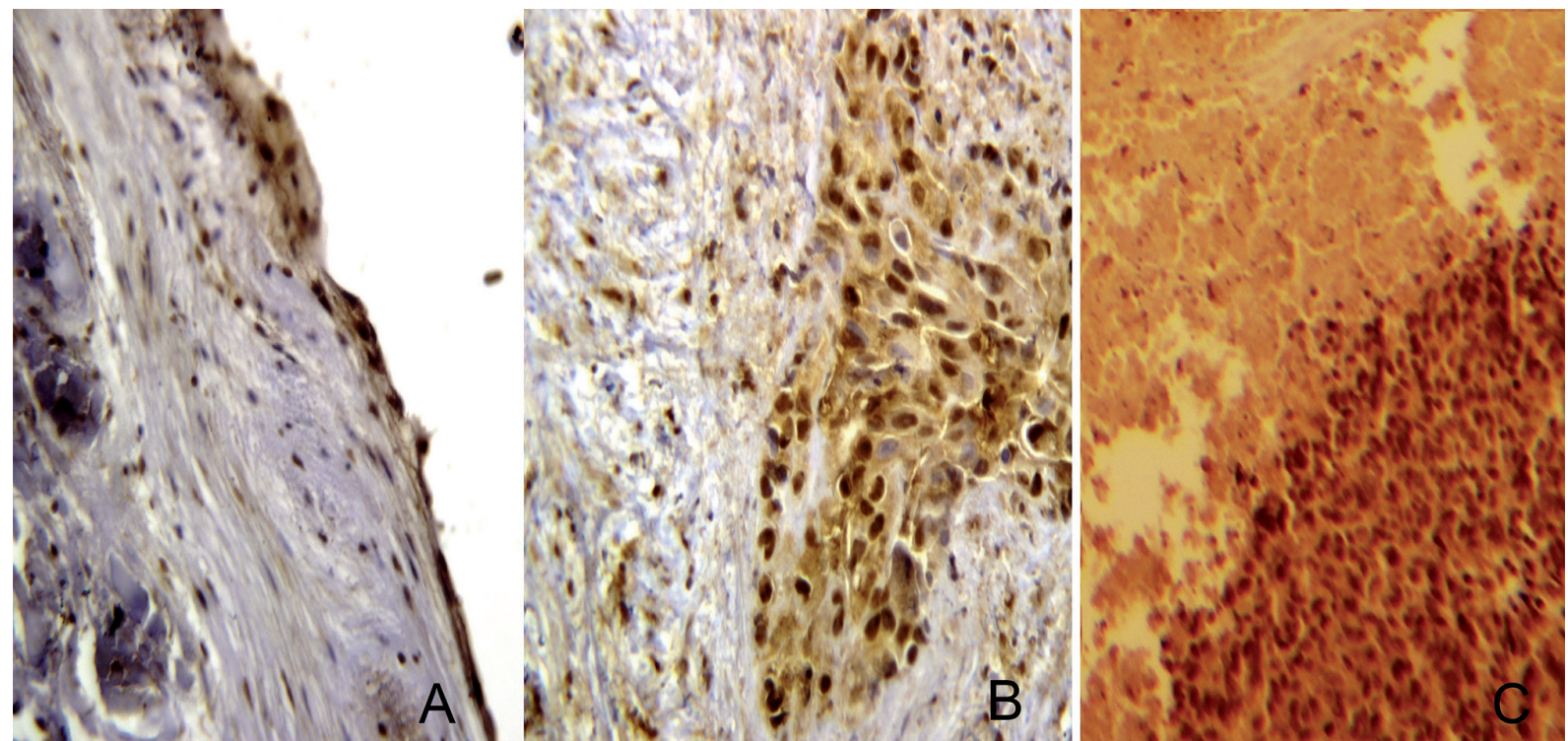

Figure 1. Immunohistochemical staining of Gankyrin protein expression in human prostate cancer tissues. Positive staining was observed as a dark brown color. (A) weak positive (1+), (B) moderately positive (2+), and (C) strongly positive (3+) staining of Gankyrin (Original magnification 400×).

The intensity of the staining was assessed in the sections and was rated from 0 (negative) to 3 (strongly positive) and the percentage of positively stained cells was also rated as: 0 , (negative), 1, (weak positive), 2, (moderate positive), and 3, (severe positive). The final index of Gankyrin expression was calculated as follow: percentagexintensity of the staining. The Gankyrin expression score was from 0 to 9; score 0:negative (-), score 1-3:weak positive $(+)$, 4-6:positive(++), and 7-9:strong positive $(+++)[15]$.
Statistical analysis. Statistical analyses were performed using the SPSS 21.0 software package (SPSS, Chicago, IL, USA). The Mann-Withney U test was applied to compare expression of p28GANK between tumor and non-cancerous tissues. The Shapiro-Wilk W-test was applied for the test of normality. If the distribution was normal, then the comparisons were made by either analysis of variance (ANOVA) followed by a Tukey or scheffe post-hoc tests or the Student's $t$ test, when appropriate. In case the distribution of variables
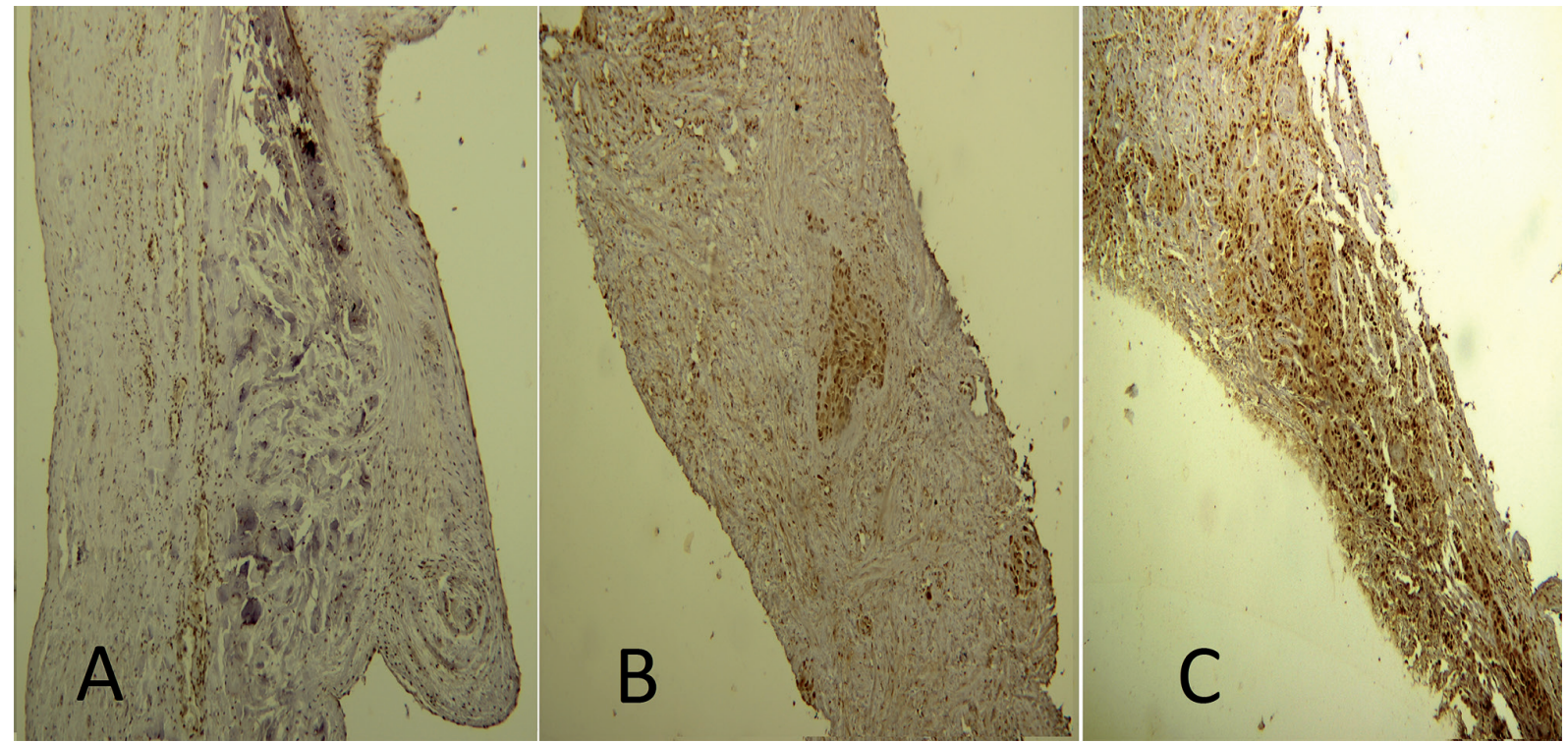

Figure 2. Gradual changes in the level and pattern of Gankyrin expression from grade1 to grade 3 as determined using IHC. A: Grade 1, B: Grade 2, C: Grade 3 (Original magnification $100 \times$ ). 
was not normal, the Kruskal-Wallis $\mathrm{H}$ test was used to identify differences between groups. Spearman rank correlation was used to assess the correlation between differentiation, histological tumor grade, Gleason score and Gankyrin expression. The value of $\mathrm{P}<0.05$ was assigned to be statistically significant ( 2 sided).

\section{Results}

Clinicopathological profiles of the patients. We examined the significance of Gankyrin expression in 55 prostate cancer patients in correlation to clinicopathologic parameters such as age, differentiation, histologic tumor grade, and Gleason score (Table 1). All histopathologic classifications as well as review of all routinely stained sections have been done by two blinded expert pathologists. This study was approved by the local ethical committee of Mashhad University of Medical Sciences.

Correlation between Gankyrin overexpression and clinicopathological characteristics in PCa tissues. The expression of Gankyrin protein was immunohistochemically examined in 55 cancerous and 20 normal prostate specimens. Gankyrin was mostly presented in the nuclear region (98\%) and occasionally in the cytoplasm (5\%) of cancerous prostate tissues. By using 10\% cut off point for staining, Gankyrin was not stained positively in the nucleus or cytoplasm of noncancerous tissue samples. The severity of nuclear staining in normal group was mainly weak (85\%) while a mild to severe intensity of staining was noted in the nucleus of cancer cells. The intensity of staining in positive cytoplasmic tissues was from weak to mild in cancerous tissues (Figure 1).

In tumor samples, overexpression of Gankyrin occurred in $81.8 \%(45 / 55)$ of patients which was significantly different from the negligible expression in normal tissues $(0 \%)$ $(\mathrm{p}<0.001$, Table 2$)$.

The majority of cases have above 50\% nuclear expression. The correlation between Gankyrin and tumor grade was assessed by spearman bivariate correlation test. Gankyrin expression was positively correlated with histological tumor grade and Gleason score $(\mathrm{p}<0.001$, Figure 2$)$.

Also with the progress in prostate cancer differentiation from well to moderate and poor differentiated as the degree of malignancy is rising, Gankyrin expression was significantly increased $(\mathrm{p}<0.001)$. No significant relationship was obtained between Gankyrin expressions with age of patients (Table 1).

\section{Discussion}

Prostate cancer is one of the most common cancers in men worldwide with a rising incidence trend in many countries [17]. In prostate cancer, as a biologically and clinically heterogeneous disease, the accumulation of genetic and epigenetic changes is necessary for transition from a focal hyperplasia to a malignant prostate tumor $[18,19]$. Clinical stage, Gleason grade and PSA are three main indicators of prognosis and making decision for therapy. Although this approach leads to a confident diagnosis in most cases, it can be improved by using the molecular markers present in the tissue to distinguish between aggressive and indolent tumors [20].

Gankyrin is an oncoprotein that interacts with some major players of cell cycle such as MDM2 [21] and CDK4 [10] and also with 26S ATPase proteasomal degradation system [22] and has an important role in the proliferation, and/or metastasis in many cancers [13, 23-26]. Gankyrin increase the ubiquitin related degradation of $\mathrm{p} 53$ by binding to MDM2. The decrease in cellular levels of p53 leads to suppression or abrogation of p53-dependent apoptosis [22]. In addition, the interaction of Gankyrin with CDK4 regulates the CDK4dependent phosphorylation of $\mathrm{pRb}$. Hyperphosphorylation of pRb activates E2F-dependent transcription of related genes [23]. So Gankyrin as a regulateor of a variety of oncogenic signaling pathways in cancer cells and accelerator of degradation of tumor suppressor proteins p53 and pRb [27] may be a unique hub integrating signaling networks with the degradation pathway. The animal models have demonstrated the important role of dual inactivation of both pathways for malignant transformation [28] and the role of this oncoprotein has been demonstrated for predicting cancer prognosis [29].

Although high expression of Gankyrin has been reported in some malignant tumors such as hepatocellular, cervical, colorectal and, glioma [14-16, 26, 29] however, to the best of our knowledge, this is the first study to demonstrate in detail an association of clinicopathological parameters and significance of Gankyrin overexpression in prostate cancer. Based on tumor architecture, the Gleason score grading system is ranking prostate cancer from well differentiated to poor differentiated. Every Gleason score has different tumor phenotype that the molecular aspects of these phenotypes should be understood more precisely.

The data of the present study showed that overexpression of Gankyrin is significantly associated with Gleason score. A significantly different staining of Gankyrin was seen in

Table 2. Immunohistochemical analysis of Gankyrin protein expression in normal and prostate cancer tissues

\begin{tabular}{lcccc}
\hline & \multicolumn{4}{c}{ Gankyrin expression } \\
\cline { 2 - 5 } Category & No. of cases & Over expression (\%) & Weak or negative expression (\%) & $P$ value \\
\hline Prostate cancer tissues & 55 & $45(81.8)$ & $10(18.2)$ & $<0.001$ \\
Non-cancerous tissues & 20 & 0 & $20(100)$ & \\
\hline
\end{tabular}


high grade prostate cancers in comparison with low garde $(p<0.001)$. These results suggest that Gankyrin protein expression strongly correlated with prostate cancer progression.

Despite the important role of Gankyrin oncoprotein in induction of cellular transformation, tumorigenesis and metastasis in many types of cancers, the data about the expression and clinicopathological significance of this oncoprotein in prostate cancer tissues is not available. The results of present study showed that Gankyrin overexpresses in prostate cancer tissues and mainly in high grade prostate tumors. So it may have a significant role in prostate cancer progress and it may be served as a useful biomarker for the identification of aggressive prostate cancers. The significant role of Gankyrin in prostate cancer suggests the possibility to make this oncoprotein as a potential target for anticancer therapies. Definitely, it is necessary to do further investigations to provide more supports of this suggestion.

Acknowledgements: This work was financially supported by a research grant (Grant No. 900971) from the Vice Chancellor of Research, Mashhad University of Medical Sciences, Mashhad, Iran. We further thank Dr. Lida Jarahi for her assistance with the statistical analysis of the data and Dr.Masoumeh Gharib for her assistance with the photos.

\section{References}

[1] SIEGEL R, NAISHADHAM D, JEMAL A. Cancer statistics, 2013. CA Cancer J Clin 2013; 63: 11-30. https://doi. org/10.3322/caac. 21166

[2] RAHIB L, SMITH BD, AIZENBERG R, ROSENZWEIG AB, FLESHMAN JM et al. Projecting cancer incidence and deaths to 2030: the unexpected burden of thyroid, liver, and pancreas cancers in the United States. Cancer Res 2014; 74: 2913-2921. https://doi.org/10.1158/0008-5472.CAN-14-0155

[3] DANIYAL M, SIDDIQUI ZA, AKRAM M, ASIF H, SULTANA $S$ et al. Epidemiology, etiology, diagnosis and treatment of prostate cancer. Asian Pac J Cancer Prev 2014; 15: 9575-9578. https://doi.org/10.7314/APJCP.2014.15.22.9575

[4] SADJADI A, NOORAIE M, GHORBANI A, ALIMOHAMMADIAN M, ZAHEDI MJ et al. The incidence of prostate cancer in Iran: results of a population-based cancer registry. Arch Iran Med 2007; 10: 481-485.

[5] MOUSAVI SM. Toward prostate cancer early detection in Iran. Asian Pac J Cancer Prev 2009; 10: 413-418.

[6] VERRAS M, SUN Z. Roles and regulation of Wnt signaling and beta-catenin in prostate cancer. Cancer Lett 2006; 237: 22-32. https://doi.org/10.1016/j.canlet.2005.06.004

[7] SARDANA G, DOWELL B, DIAMANDIS EP. Emerging biomarkers for the diagnosis and prognosis of prostate cancer. Clin Chem 2008; 54: 1951-1960. https://doi.org/10.1373/ clinchem.2008.110668

[8] HOOGLAND AM, KWELDAM CF, VAN LEENDERS GJ. Prognostic histopathological and molecular markers on prostate cancer needle-biopsies: a review. Biomed Res Int 2014; 341324 .
[9] HIGASHITSUJI H, ITOH K, NAGAO T, DAWSON S, NONOGUCHI K et al. Reduced stability of retinoblastoma protein by gankyrin, an oncogenic ankyrin-repeat protein overexpressed in hepatomas. Nat Med 2000; 6: 96-99. https:// doi.org/10.1038/71600

[10] LI J, TSAI MD. Novel insights into the INK4-CDK4/6-Rb pathway: counter action of gankyrin against INK4 proteins regulates the CDK4-mediated phosphorylation of Rb. Biochem 2002; 41: 3977-3983. https://doi.org/10.1021/bi011550s

[11] IWAI A, MARUSAWA H, KIUCHI T, HIGASHITSUJI H, TANAKA K et al. Role of a novel oncogenic protein, gankyrin, in hepatocyte proliferation. J Gastroenterol 2003; 38: 751-758. https://doi.org/10.1007/s00535-003-1141-8

[12] MOSAVI LK, CAMMETT TJ, DESROSIERS DC, PENG ZY. The ankyrin repeat as molecular architecture for protein recognition. Prot Sci 2004; 13: 1435-1448. https://doi. org/10.1110/ps.03554604

[13] GAO L, XIE H, DONG L, ZOU J, FU J et al. Gankyrin is essential for hypoxia enhanced metastatic potential in breast cancer cells. Mol Med Rep 2014; 9: 1032-1036. https://doi. org/10.3892/mmr.2013.1860

[14] FU XY, WANG HY, TAN L, LIU SQ, CAO HF et al. Overexpression of p28/gankyrin in human hepatocellular carcinoma and its clinical significance. World J Gastroenterol 2002; 8: 638-643. https://doi.org/10.3748/wjg.v8.i4.638

[15] LIU Y, ZHANG J, QIAN W, DONG Y, YANG Y et al. Gankyrin is frequently overexpressed in cervical high grade disease and is associated with cervical carcinogenesis and metastasis. PLoS One 2014; 9: e95043. https://doi.org/10.1371/journal. pone.0095043

[16] TANG S, YANG G, MENG Y, DU R, LI X, et al. Overexpression of a novel gene gankyrin correlates with the malignant phenotype of colorectal cancer. Cancer Biol Ther 2010; 9: 88-95. https://doi.org/10.4161/cbt.9.2.10283

[17] FERLAY J, SOERJOMATARAM I, DIKSHIT R, ESER S, MATHERS C et al. Cancer incidence and mortality worldwide: sources, methods and major patterns in GLOBOCAN 2012. Int J Cancer 2015; 136, E359-E386. https://doi.org/10.1002/ ijc. 29210

[18] KOOCHEKPOUR S. Genetic and epigenetic changes in human prostate cancer. Iran Red Crescent Med J 2011; 13: 80-98.

[19] SHEN MM, ABATE-SHEN C. Molecular genetics of prostate cancer: new prospects for old challenges. Genes Dev 2010; 24: 1967-2000. https://doi.org/10.1101/gad.1965810

[20] CULIG Z. Distinguishing indolent from aggressive prostate cancer. Recent Results Cancer Res 2014; 202: 141-147. https:// doi.org/10.1007/978-3-642-45195-9 17

[21] QIU W, WU J, WALSH EM, ZHANG Y, CHEN CY et al. Retinoblastoma protein modulates gankyrin-MDM2 in regulation of p53 stability and chemosensitivity in cancer cells. Oncogene 2008; 27: 4034-4043. https://doi.org/10.1038/ onc. 2008.43

[22] DAWSON S, APCHER S, MEE M, HIGASHITSUJI H, BAKER R et al. Gankyrin is an ankyrin-repeat oncoprotein that interacts with CDK4 kinase and the S6 ATPase of the 26 S proteasome. J Biol Chem 2002; 277: 10893-10902. https:// doi.org/10.1074/jbc.M107313200 
[23] MENG Y, HE L, GUO X, TANG S, ZHAO X et al. Gankyrin promotes the proliferation of human pancreatic cancer. Cancer Lett 2010; 297: 9-17. https://doi.org/10.1016/j.canlet.2010.04.019

[24] CHEN J, BAI M, NING C, XIE B, ZHANG J et al. Gankyrin facilitates follicle-stimulating hormone-driven ovarian cancer cell proliferation through the PI3K/AKT/HIF-1alpha/cyclin D1 pathway. Oncogene 2015; 35: 2506-2517. https://doi. org/10.1038/onc.2015.316

[25] LUO X, CHEN L, DAI J, GAO Y, WANG H et al. Gankyrin gene deletion followed by proteomic analysis: insight into the roles of Gankyrin in Tumorigenesis and Metastasis. BMC Med Genomics 2012; 5: 36. https://doi.org/10.1186/1755-8794-5-36

[26] YANG Y, ZHANG C, LI L, GAO Y, LUO X et al. Up-regulated oncoprotein P28GANK correlates with proliferation and poor prognosis of human glioma. World J Surg Oncol 2012; 10: 169. https://doi.org/10.1186/1477-7819-10-169

[27] WANG X, JIANG B, ZHANG Y. Gankyrin regulates cell signaling network. Tumour Biol 2016; 37: 5675. https://doi. org/10.1007/s13277-016-4854-Z

[28] YANG G, RAJADURAI A, TSAO H. Recurrent patterns of dual RB and p53 pathway inactivation in melanoma. J Invest Dermatol 2005; 125: 1242-1251. https://doi.org/10.1111/ j.0022-202X.2005.23931.X

[29] ZHAO X, LIU F, ZHANG Y, LI P. Prognostic and clinicopathological significance of Gankyrin overexpression in cancers: evidence from a meta-analysis. OncoTargets Ther 2016; 9: 1961-1968. https://doi.org/10.2147/OTT.S101687 